\title{
DEPOIMENTO: UMA TRAJETÓRIA PARA O PRESENTE ${ }^{1}$
}

MARLY RODRIGUES, MEMÓRIAS ASSESSORIA E PROJETOS, SÃO PAULO, SÃO PAULO, BRASIL.

Historiadora pela Faculdade de Filosofia, Letras e Ciências Humanas da Universidade de São Paulo (FFLCHUSP, São Paulo, SP). Mestre pela mesma instituição (FFLCH-USP, São Paulo, SP). Doutora pelo Instituto de Filosofia e Ciências Humanas da Universidade Estadual de Campinas (IFCH-Unicamp, Campinas, SP).Titular da empresa Memórias Assessoria e Projetos.

E-mail: marly@mem.com.br

DOI

http://dx.doi.org/10.11606/issn.1980-4466.v0i23p295-302

1. Depoimento proferido durante a Jornada Revista CPC: 10 anos de reflexão sobre o patrimônio cultural - Mesa 2: PATRIMÔNIO CULTURAL - Uma trajetória para o presente - Marly Rodrigues (Memória Assessoria e Projetos); A complexidade do patrimônio universitário - Beatriz Mugayar Khül (Faculdade de Arquitetura e Urbanismo da Universidade de São Paulo); O patrimônio no âmbito da cultura e extensão universitária - José Tavares Correia de Lira (Faculdade de Arquitetura e Urbanismo da Universidade de São Paulo). Evento realizado pelo Centro de Preservação Cultural da Universidade de São Paulo, em 22 de novembro de 2016, na Casa de Dona Yayá. 
Tecer considerações sobre o desenvolvimento da proteção de bens culturais no estado de São Paulo exigiria maior reflexão que a aqui expressa, tendo em vista a diversidade de atuação dos poderes públicos municipal, estadual e federal, e as inúmeras implicações, quer do ponto de vista técnico, quer do político, que isso envolve.

Assim, optei por considerar apenas, e de forma ligeira, a atuação do Conselho de Defesa do Patrimônio Histórico Arqueológico, Artístico e Turístico (Condephaat). Um olhar retrospectivo mostra um saldo positivo no que se refere à proteção de bens. Talvez não seja possível dizer o mesmo em relação às intervenções de conservação e restauro e em relação à valorização do patrimônio, aspecto esse muito pouco considerado nas ações até o momento desenvolvidas.

Ao menos até 2005 não foram poucas as propostas de melhoria das condições de trabalho e ampliação do alcance das ações de proteção apresentadas aos sucessivos secretários de Cultura por técnicos e membros do Conselho, sem qualquer resultado. A última reorganização da Secretaria Estadual de Cultura (Decreto no 50.941, de 2006) também não contemplaria esse aspecto. Uma das unidades então criadas, a de Preservação do Patrimônio Histórico (?! não seria mais adequado cultural) - UPPH se tornou um braço técnico do Conselho e, assim como esse, é diretamente subordinada ao secretário de Cultura. Por hipótese, essa situação 
propiciaria condições de aprimoramento do desempenho do órgão, o que não se efetivou. E, se considerarmos a situação anterior, na qual o setor técnico era subordinado ao Conselho e esse ao secretário, a reorganização permitiu centralização e maior controle das atividades pela Secretaria. Em período mais recente houve esforços para ampliar as formas jurídicas de reconhecimento de valor cultural - em 2011, Decreto no 57.439, trata do registro de bens culturais de natureza imaterial; em 2015 a Resolução SC-12, de Lugar de Interesse Cultural.

Os tombamentos realizados pelo Condephaat deixam entrever tropeços decorrentes da descontinuidade entre gestões, de limitações legais e de estrutura administrativa e a diversidade dos contextos sociais no decorrer dos 47 anos de atividades, bem como as mudanças conceituais que influíram na composição do conjunto de bens protegidos.

Entre os bens tombados até 1979 havia dois centros históricos, de Cananéia e São Sebastião; obras de arte (Benedito Calixto, 1969; Almeida Júnior 1970); acervos de arte (Capela do Hospital das Clínicas/obras de Brecheret, 1970; acervo do Museu de Arte de São Paulo, 1973; a coleção artística do Museu Paulista da USP, em 1973, desde a década de 1940, tombada pelo Iphan); coleção arqueológica e etnológica do Museu de Arqueologia e Etnologia da USP. Considerando-se os tombamentos exofficio, até 1979 a maioria dos bens tombados eram palácios e palacetes do século XIX, de famílias abastadas, residências de personalidades, capelas e igrejas.

Outros núcleos históricos seriam tombados na década de 1980, de acordo com um projeto inspirado no programa federal de revitalização de cidades históricas. Além das casas selecionadas por suas características arquitetônicas e estéticas, foram tombadas sedes de fazendas, de sítios, naturalmente igrejas e capelas - a exclusividade de representação da religião Católica Apostólica Romana no patrimônio seria rompida apenas em 1990, com o tombamento da casa de culto de origem africana, Axé Ilê Obá -; a esses foram acrescidas tipologias ainda inéditas: cemitérios, teatros, hospitais e três sambaquis em Cananéia (1987), de valor arqueológico. E, também, no ano de 1985, em uma ação inovadora e ousada, a Serra do Mar.

A década de 1980 pode ser caracterizada como um período em que 
foram ampliados os valores culturais que justificam os tombamentos. Tomemos como exemplo o caso do Mercado Municipal de Campinas, tombado em 1983. O professor Antonio Augusto Arantes, então assessor do Conselho, observou que, ao lado da importância histórica e arquitetônica desse edifício projetado pelo escritório Ramos de Azevedo, era grande seu significado para o cotidiano daquela cidade. Lá se dava o encontro de todas as camadas sociais e se desenvolviam práticas comerciais e formas de sociabilidades específicas, argumentos esses que sustentaram a atribuição de valores pelo conselheiro relator, professor Titarelli.

Outro exemplo, o do bairro do Cafundó, em Sorocaba, remanescente de um quilombo, foi analisado sob um ponto de vista histórico-antropológico e tombado em 1990. Picinguaba, vila tombada em 1983, situada em área que sofrera enorme impacto com a abertura da estrada litorânea na década de 1970, polarizaria opiniões entre a necessidade de proteção de toda a área por ela ocupada e o entorno para a permanência das práticas culturais locais, e apenas o tombamento de unidades habitacionais características do litoral paulista lá erguidas, posição que prevaleceu, embora na análise tenham sido ressaltados o sentido antropológico da proteção. A decisão não evitou a transformação cultural, e espacial, decorrente do turismo.

O que se expressava nas discussões do Condephaat nessa década de democratização do país e de profunda mudança de valores sociais - em parte relacionados ao processo de globalização e universalização da cultura, que incluiu a ampliação do universo "patrimonialisável” e a criação da categoria patrimônio da humanidade - era uma disputa pela ampliação dos valores culturais atribuído aos bens, o que é de extrema importância se considerarmos que isso orienta a construção da memória coletiva. Tratava-se de definir conceitos e procedimentos que traçassem o perfil de uma política de preservação valorizadora das práticas culturais e do meio ambiente, que promovesse a melhoria da qualidade de vida.

Em 1983, haviam sido tombadas as Serras do Japi, de Itapetinga, de Boturuna, atestando uma significativa ampliação dos valores culturais que referenciavam os tombamentos, o que se deve a presença de olhares de disciplinas de conhecimento que havia pouco atuavam na preservação de bens culturais: a geografia e a antropologia. A partir desses pontos de 
vista se inverteu temporariamente a direção da atuação do Condephaat, do passado para o presente, ou, se quiserem, para o passado integrado ao presente, visando propiciar a continuidade de práticas culturais e maiores cuidados com o ambiente e, em especial, no dizer do professor Aziz Ab'Saber, com "a memória da natureza”.

As discussões e embates desse período instigavam a busca de renovação das formas de trabalho, a aproximação com outros setores da administração estadual, com as populações locais buscando ampliar sua participação... Há vários exemplos disso.

Santana do Parnaíba, onde as dificuldades de aceitação das restrições impostas pelo tombamento da cidade não foram contornadas nem com a instalação de um escritório local do Condephaat é um deles. Aí foi realizada uma pesquisa de caráter antropológico que explicou as profundas razões culturais da resistência; posteriormente, essa pesquisa foi base para um trabalho acadêmico pioneiro realizado por uma socióloga integrante do corpo técnico, Naira Morgado. A partir de então, felizmente, ampliou-se a produção acadêmica sobre a construção do patrimônio cultural paulista, aspecto de grande importância para a apreciação crítica dessa prática.

Outro exemplo é o trabalho desenvolvido em Bananal; no ano de 1982, paralelamente ao estudo de tombamento, os técnicos realizaram ações de esclarecimento da importância do tombamento e de valorização da cultura local, voltadas para professores e alunos do ensino primário, por meio de palestras e atividades lúdicas; para a população em geral, através de uma exposição que mesclava documentos históricos e outros resultantes dos estudos realizados com artesanato, doces... e apresentação pública de grupos de congada e outras danças populares, sempre com apoio de parte da população. Além disso, em parceria com a Cetesb, promoveramse discussões e propuseram-se soluções sobre questões ambientais.

Buscou-se aí operar a partir de uma noção ampla de cultura e valorizar manifestações que dessem ao conjunto da população a oportunidade de reconhecer-se, uma vez que, para parte dela, os casarões, ao mesmo tempo despertavam orgulho e ressentimentos, uma vez que, simbolicamente remetiam às desigualdades desde o período cafeicultor presentes naquela sociedade. Buscava-se a aproximação com os diferentes segmen- 
tos da sociedade local e estender a idéia de patrimônio cultural para a paisagem. No curto período em que Aziz Ab' Saber presidiu o Conselho (nov. 1982- mar.1983), foi nomeada uma comissão de moradores cuja função era manter contato constante entre a população e o Condephaat. Essa medida foi considerada ilegal e, após a gestão Arantes (maio 1983out. 1984) as atividades visando esclarecer a população e valorizar o patrimônio, não apenas em Bananal, mas em outros locais, foram declinando, pois eram vistas como algo fora da competência do órgão. Possivelmente o fossem em relação ao corpo técnico, mas não ao órgão, ao qual compete, também, a valorização do patrimônio.

Os esforços de renovação apontados, além de inúmeros outros aqui não abordados, não foram integrados aos procedimentos de rotina. Portanto, não lograram romper o isolamento que vem caracterizando a prática preservacionista no Brasil, cujo horizonte tende a se esgotar em si mesma. $\mathrm{O}$ isolamento não se expressa apenas nas ações, mas por meio da flutuação do lugar, em geral secundário, ocupado pelos órgãos de preservação em diferentes governos, mas, também, por exemplo, através da ausência do tema "preservação" nos programas de candidatos a cargos executivos e legislativos. São raros aqueles que mencionam em suas propostas de gestão a proteção ao patrimônio histórico-arquitetônico ou a preservação da memória social - essa envolvendo arquivos, bibliotecas e museus. Mexer com a preservação da memória social é bolir no vespeiro dos interesses econômicos e dar apoio ao desenvolvimento de consciências coletivas. Quer do ponto de vista material, quer do simbólico, as ações de proteção de bens culturais não oferecem bons dividendos políticos e raramente despertam interesse dos que concorrem a cargos eletivos.

Contudo, ao mesmo tempo em que a proteção jurídica, atributo exclusivo do poder público, permanece restrita ao tombamento e ao registro e desdenha as possibilidades do inventário enquanto instrumento de proteção, ainda que com oscilações, é perceptível o crescimento do interesse de instituições e de setores organizados da sociedade na preservação de bens culturais.

Isso não diminui a necessidade de uma eficiente política pública de construção da memória, se é que ainda não abdicamos de construir uma sociedade mais democrática e solidária. Trata-se de um processo no qual, 
sem dúvida, a parte substancial cabe a toda a sociedade, mas que não se desenvolverá sem que aos profissionais da memória rompam a repetição de mantras e repensem propositivamente o sentido social do preservar e a adequação dos órgãos de preservação aos tempos atuais, tendo em vista maior eficácia dessa ação em um Estado que, cada vez menos se ocupa do bem-estar coletivo e em uma sociedade em que o passado é visto como algo distante e acabado e vem se reduzindo a objeto de consumo .

A fase atual é de acirramento dos efeitos da globalização; isso se reflete em todos os setores da vida, da organização do trabalho à cultura, o que afeta subjetividades, identidades e o sentido de "coletivo", tópicos diretamente relacionados à construção da memória social. O processo em curso impõe reflexão e ação no sentido de reconstruir referências, uma vez que as que apoiaram as sociedades modernas já foram ou estão sendo desfeitas. $^{2}$

Mais que nunca não cabe continuar atuando a partir da ideia de missão que ainda perpassa a atuação preservacionista. Ela foi gerada quando, na década de 1930, poucos intelectuais assumiam a definição do que era necessário ensinar àqueles que eram tidos como pessoas que nada sabiam. Em graus diversos, a missão educadora ainda sustenta a idéia de salvar artefatos isolados, que compõem uma espécie de mostruário denominado "patrimônio", cuja conexão entre as peças não é evidente. É possível que no quadro de fragmentação em que hoje vivemos, a preservação se imponha a partir de unidades mais complexas, como o artefato "cidade", expressão de uma totalidade em contínua construção, como o é a própria cultura.

Em favor de uma idéia conservadora, os órgão de proteção ao patrimônio têm deixado de lado a adoção/aplicação de novos conceitos e a elaboração de procedimentos com eles coerentes, de modo a realçar o patrimônio como uma via de compreensão do presente, e de integração desse com o passado, condição necessária à percepção do tempo histórico, hoje acelerado pela tecnologia. Tempo histórico que deveria ser observado pelos responsáveis pela preservação de bens culturais como a dimensão em

2. BAUMAN, Zygmunt. Identidade. Rio de Janeiro: Jorge Zahar, 2005. Introdução, Benedetto Vecchi, p. 7-14 
que se redesenha a relação entre a sociedade e seu passado e não como dimensão promotora da destruição e de "remanescentes".

A adequação das ações de preservação às condições da sociedade contemporânea parece exigir também o rompimento com o "atavismo metodológico", o que, além de definição de um corpo de conceitos e procedimentos, inclui etapas sistemáticas e contínuas de identificação de bens culturais e inventários. Só a partir deles se torna possível estabelecer critérios coerentes de proteção, preservação e valorização de bens culturais e, o que é de extrema importância, organizar a gestão do patrimônio.

Nesse sentido se mostra importante o rompimento com o "conservadorismo institucional" que fez com que se replicasse o Decreto-lei no 25 , do que resulta a sobreposição de funções institucionais e, muitas vezes, gera conflitos entre as regras definidas pelas três instâncias administrativas sobre um mesmo objeto. A eficiência da preservação aponta a necessidade de diferenciação do caráter/função dos órgãos, tornando-as dinâmicos e complementares entre si e com os demais órgãos de cada instância administrativa que envolvam a gestão do território.

Para atender à situação atual da sociedade, ocasionada pelas amplas mudanças antes referidas e, do ponto de vista local, pelas necessidades de melhoria da qualidade ambiental e de vida, parece não ter sido suficiente diversificar a representação cultural do universo de bens tombados ou ampliar seu número. Isso não mais significou, de fato, a democratização do direito à memória, uma vez que construída a partir do presente, essa envolve valores culturais hodiernos.

Ao valorizarmos um bem como representação do passado e ao projetarmos a finalidade da preservação como uma ação voltada para o futuro (preservar para as gerações futuras é uma justificativa que se tornou censo comum!), negamos a preservação como prática social reveladora dos valores sociais do presente. Em consequência, enfraquecemos o potencial transformador da memória e os olhares críticos sobre o presente. Sem eles, não se abrem as possibilidades de exercício de direitos e se escamoteia um fato: precisamos do passado integrado ao presente, de modo a esclarecer o sentido desse último. 